\title{
Z Isomer
}

National Cancer Institute

\section{Source}

National Cancer Institute. Z Isomer. NCI Thesaurus. Code C92194.

A double bond with its highest priority side groups on the same sides. 